\title{
Gefitinib, as a New Stent Coating Material, Specifically Inhibits Smooth Muscle Cells Proliferation Through Inhibition of EGFR/Akt Pathway Phosphorylation
}

\author{
F. Li, S.Y. Wang, J. Luo, Z.X. Wu, T. Xiao, O. Zeng, \\ J. Yang* \\ The First Affiliated Hospital of University of South China \\ Hengyang, China, 421001
}

\author{
C. Chu \\ The Second Affiliated Hospital of University of South China \\ Hengyang, China, 421001 \\ *Corresponding author
}

\begin{abstract}
The objective of this paper is to investigate the effects of gefitinib as a new stent coating material on proliferation of smooth muscle cells and the expression and phosphorylation of EGFR/Akt protein. Rat smooth muscle cells were cultured in medium with gefitinib $\left(10^{-2} \mu \mathrm{mol} / \mathrm{L}-10 \mu \mathrm{mol} / \mathrm{L}\right)$ for $24 \mathrm{~h}-72 \mathrm{~h}$. MTT assay was used to test the inhibition of cell proliferation. Western-blot was used to detect the expression of EGFR, Akt, phosphorylated EGFR (p-EGFR) and phosphorylated Akt (p-Akt). MTT assay showed that the inhibitory effect of gefitinib on smooth muscle cells' proliferation was in a time and concentration dependent manner. Western-blot showed the expression of EGFR and Akt has no significant change between gefitinib group and paclitaxel group in smooth muscle cells, but gefitinib could significantly inhibit the phosphorylation of EGFR and Akt in smooth muscle cells compared with paclitaxel. It is concluded that Gefitinib could significantly suppress the proliferation of smooth muscle cells; the mechanism might be by inhibiting the phosphorylation of EGFR and Akt.
\end{abstract}

Keywords-coating material; cytotoxicity; stent; gefitinib; smooth muscle cells; phosphorylation

\section{INTRODUCTION}

Percutaneous Coronary Intervention(PCI)is the main method to treat the coronary heart disease at present. Drug-eluting stents have been widely used to reduce the occurrence of in-stent restenosis. However, as stent coating materials of drug-eluting stents, paclitaxel and rapamycin may cause endothelial damage and stent thrombosis, which is due to the non-selective cytotoxicity of the coating materials of the drug-eluting stent. To develop new stent coating materials, it is critical to selectively inhibit smooth muscle cells proliferation and makes the effect to endothelial repair decrease to the minimum extent.

A main mechanism of restenosis after Percutaneous Coronary Intervention (PCI) is that smooth muscle cells migrate to injured vascular intima and keep on proliferating after phenotypic transformation[1,2] while the proliferation and migration of endothelial cells contribute to repair injured vascular intima and may prevent from thrombosis[3]. Currently, the main research direction of prevention and treatment on restenosis is to effectively inhibit the excessive proliferation of smooth muscle cells (SMCs) and reduce damage to endothelial cells (ECs). Epidermal Growth Factor Receptor (EGFR) is involved in the phenotypic transformation of smooth muscle cells and plays an important role in the regulation of signal pathway during the development of restenosis[4]. Gefitinib as an EGFR inhibitor can bind to intracellular region sites of EGFR tyrosine kinase together with ATP in a competitive manner, and obviously inhibits autophosphorylation of tyrosine kinase on surface receptor of EGFR transmembrane cell so as to inhibit cell proliferation[5]. EGFR is required for Akt activation. Blocking EGFR signalling amplifies the apoptotic response to TGF-beta1. Our previous research had shown that Gifitinib could inhibit the proliferation of SMCs without effecting ECs. This experiment is to investigate the effects and possible mechanisms of gefitinib on proliferation of smooth muscle cells in order to provide new ideas to clinically prevent and reduce restenosis after PCI.

\section{MATERIALS AND METHODS}

\section{A. Cells and Main Reagents}

Rat vascular smooth muscle cells were provided by the Experimental Animal Center, University of South China. Gefitinib and paclitaxel were purchased from AstraZeneca (England). Antibodies for EGFR, Akt, phospho-EGFR and phospho-Akt were purchased from Cell Signaling Technology (Beverly, MA).

\section{B. Cell Culture}

Rat vascular smooth muscle cells were cultured in medium, supplemented with $10 \%$ FBS at $37^{\circ} \mathrm{C}$ in a humidified incubator with $5 \% \mathrm{CO}_{2}$. When they grew to $80 \%$ area of the Petri dish, the cells were subcultured 2 to 3 times after digestion with $0.25 \%$ trypsin.

\section{MTT Assay}

About $2 \times 10^{4} / \mathrm{ml}$ cell suspension was made from logarithmic phase cells, $200 \mu \mathrm{l} /$ hole of it was added to 96 well plates, then cultured in the incubator. Two hours later after cells were adhered, Gifitinib and paclitaxel with different concentrations $\left(10^{-2} \mu \mathrm{mol} / \mathrm{L}, 10^{-1} \mu \mathrm{mol} / \mathrm{L}, 1 \mu \mathrm{mol} / \mathrm{L}, 10 \mu \mathrm{mol} / \mathrm{L}\right)$ 
were added into the cells respectively and wait for 48 hours. Meanwhile, Gifitinib and paclitaxel $(1 \mu \mathrm{mol} / \mathrm{L})$ were added to smooth muscle cells for $24 \mathrm{~h}, 48 \mathrm{~h}$ and $72 \mathrm{~h}$, respectively. After this, $20 \mu \mathrm{l}$ MTT was added into every hole, and 4 hours later, supplemented with $150 \mu \mathrm{l} 10 \%$ SDS. The absorbance at 490 nm was recorded using a 96-well microplate reader.

\section{Western Blot Analysis}

Cells were lysed in protein lysis buffer and then were quantified. Each sample was subjected to $10 \%$ SDS-PAGE and the separated proteins were transferred to PVDF membranes. The membranes were incubated with EGFR, Akt, phospho-EGFR and phospho-Akt antibody respectively. Then primary antibodies were detected with a secondary antibody and finally the membranes were subjected to chemiluminescence detection assay.

\section{E. Statistical Analysis}

Data were shown as means \pm Standard Error (SE). The inhibition data of Gifitinib and paclitaxel on smooth muscle cells were analyzed by SPSS (V18.0) using one-way analysis of variance (ANOVA). $P<0.05$ was considered to be statistically significant.

\section{RESULTS}

\section{A. Gefitinib Inhibits the Proliferation of Smooth Muscle Cells}

Smooth muscle cells were exposed to Gefitinib with four different concentrations (from $10-2 \mu \mathrm{mol} / \mathrm{L}$ to $10 \mu \mathrm{mol} / \mathrm{L}$ ) for $48 \mathrm{~h}$. It showed that Gefitinib inhibited the proliferation of smooth muscle cells in a concentration-dependent manner (Figure 1). Then smooth muscle cells were dealt with Gefitinib $(1 \mu \mathrm{mol} / \mathrm{L})$ for $24 \mathrm{~h}, 48 \mathrm{~h}$ and $72 \mathrm{~h}$ respectively. And the results showed that Gefitinib could inhibit the proliferation of smooth muscle cells in a time-dependent manner (Figure 1).
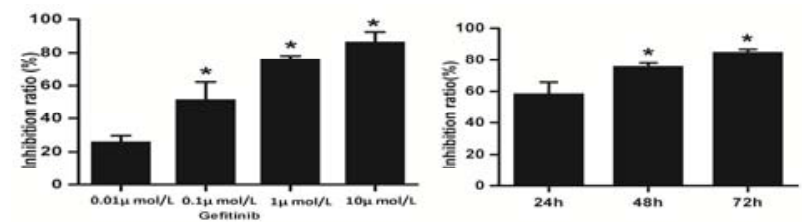

FIGURE I. THE INHIBITION EFFECT OF GEFITINIB ON PROLIFERATION OF SMOOTH MUSCLE CELLS WITH DIFFERENT CONCENTRATIONS AND TIMe. $\left({ }^{*} \mathrm{P}<0.05\right.$, VS $0.01 \mu \mathrm{mol} / \mathrm{L}$ GROUP OR 24h GROUP).

\section{B. Gefitinib Affects the Phosphorylation of EGFR of Smooth Muscle Cells}

Western-blot was used to test the expression level of EGFR and pEGFR after smooth muscle cells had been treated with Gefitinib for $48 \mathrm{~h}$. The expression of EGFR showed no statistical difference between the two groups $(P>0.05)$, while expression of pEGFR in Gefitinib group was much less than the control group. Gefitinib inhibited EGFR protein phosphorylation of smooth muscle cells obviously $(P<0.05)$ (Figure2).

\section{Gefitinib Affects the Phosphorylation of Akt of Smooth Muscle Cells}

Western-blot was used to test expression level of Akt and
pAkt after smooth muscle cells had been treated with Gefitinib for $48 \mathrm{~h}$. It showed that expression of pAkt in smooth muscle cells was much lower by treating with Gefitinib $(P<0.05)$ while expression of Akt showed no statistical difference $(P>0.05)$. Gefitinib could inhibit Akt protein phosphorylation of smooth muscle cells (Figure2).
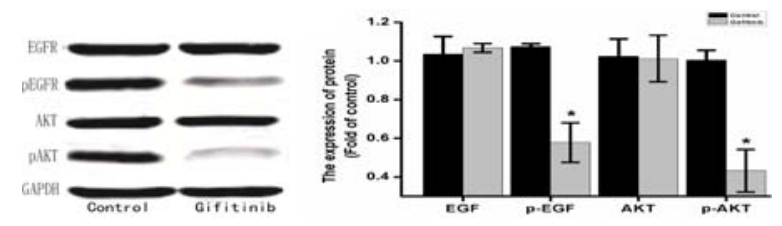

FIGURE II. THE EFFECTS OF GIFITINIB ON EXPRESSION AND PHOSPHORYLATION OF EFGR/AKT OF SMOOTH MUSCLE CELLS. $\left({ }^{*} \mathrm{P}<0.05\right.$, VS CONTROL GROUP).

\section{DISCUSSION}

Percutaneous Coronary Intervention (PCI) has become an important treatment method for vascular reconstruction. It can significantly reduce the incidence of acute cardiac events and related mortality. However, it brings a high rate of restenosis after PCI, in which its main mechanism is related with the migration of smooth muscle cells to intima and its proliferation after phenotypic transformation. Drug-eluting stents can inhibit proliferation of smooth muscle cells and then significantly reduce the rate of restenosis after PCI [6]. Paclitaxel and rapamycin, as a new stent coating material, have been proven to be effective in inhibiting VSMCs proliferation and now are widely used in drug-eluting stents to prevent restenosis after PCI. However, there is still something unsatisfactory. Though paclitaxel and rapamycin can inhibit proliferation of smooth muscle cells, it would either produce significant cytotoxicity on endothelial cells to inhibit endothelial repair and result in incomplete or delayed stent endothelialization. Therefore, in order to prevent stent restenosis and thrombosis, it is critical to choose a drug that can inhibit the proliferation and migration of smooth muscle cells to the greatest extent and meanwhile inhibit endothelial repair to the minimum extent. Our previous researches had shown that Gifitinib, an EGFR inhibitor, could effectively inhibit the proliferation of smooth muscle cells; meanwhile, its inhibition on endothelial cells is significantly small. Gefitinib may bind to intracellular region of EGFR to inhibit phosphorylation of EGFR and further proliferation of smooth muscle cells. EGFR is a very important outpost of information transfer [7]. Once the receptor binds to its ligand, it can promote cellular migration, differentiation and proliferation [8]. Therefore, it is possible that the AKT pathway plays a role in vascular smooth cell proliferation and apoptosis, and its abnormality leads to restenosis. In addition, recent studies have suggested that AKT activation is facilitated via EGFR ligand secretion, EGFR activation and subsequent c-Src phosphorylation. In this study, gefitinib could suppress the phosphorylation of EGFR protein on surface of smooth muscle cells, and it has a dose-time dependent manner. It is also observed that Akt protein expression of smooth muscle cells has been reduced by gefitinib, particularly obvious in down-regulation of the expression of phosphorylated Akt protein. The results suggest that gefitinib has a significant inhibitory effect on phosphorylation of EGFR/Akt pathway of 
the smooth muscle cells, which may be related to its relatively selective cytotoxic effect.

It can be concluded from the obtained results that gefitinib, as an EGFR inhibitor, can influence phosphorylation of its downstream Akt protein by inhibiting the auto-phosphorylation of EGFR, and then inhibit celluar proliferation. EGFR is one of the key signaling pathways in excessive proliferation of smooth muscle cells. It can be observed in this experiment that, either EGFR targeted drugs gefitinib or TS-oriented drug, their specificity may inhibit proliferation of smooth muscle cells. The cytotoxic effects of both drugs on endothelial cells are relatively small, while TS is a drug with more potential drug. These cytotoxic drugs particularly targeting the smooth muscle cells are expected to become the next generation of stent eluting material to displace with the old non-specific cytotoxic drugs, such as paclitaxel and rapamycin.

\section{ACKNOWLEDGEMENTS}

This work was financially supported by the National Natural Science Foundation of China (81270181) and National Natural Science Foundation of China (81202830).

\section{REFERENCES}

[1] Tsaousi A, Mill C, George SJ. The Wnt pathways in vascular disease: lessons from vascular development[J]. Current opinion in lipidology,2011,22:350-7.

[2] Orr AW, Hastings NE, Blackman BR, et al. Complex regulation and function of the inflammatory smooth muscle cell phenotype in atherosclerosis[J]. Journal of vascular research,2010,47:168-80.

[3] Carmeliet P, Moons L, Stassen JM, et al. Vascular wound healing and neointima formation induced by perivascular electric injury in mice $[\mathrm{J}]$. The American journal of pathology,1997,150:761-76.

[4] Igura T, Kawata S, Miyagawa J, et al. Expression of heparin-binding epidermal growth factor-like growth factor in neointimal cells induced by balloon injury in rat carotid arteries[J]. Arteriosclerosis, thrombosis, and vascular biology, 1996,16:1524-31.

[5] Burton A. What went wrong with Iressa?[J]. The lancet oncology,2002,3:708.

[6] Landau C, Lange RA, Hillis LD. Percutaneous transluminal coronary angioplasty[J]. The New England journal of medicine,1994,330:981-93.

[7] Parise Junior O, Carvalho LV, Miguel RE, et al. Prognostic impact of p53, c-erbB-2 and epidermal growth factor receptor on head and neck carcinoma[J]. Sao Paulo medical journal $=$ Revista paulista de medicina,2004,122:264-8.

[8] Cullen M. Second-line treatment options in advanced non-small cell lung cancer: current status[J]. Seminars in oncology,2006,33:S3-8. 